\title{
Sudden Hemianopsia Secondary to Ethmoid Sinus Mucocele
}

\author{
Ligia Morganti $^{1}$ Leandro Evangelista ${ }^{1}$ Roberto Guimaraes ${ }^{1}$ Paulo Crosara ${ }^{1}$ \\ ${ }^{1}$ Department of Otorhinolaryngology, Universidade Federal de Minas \\ Gerais, Belo Horizonte, Minas Gerais, Brazil \\ Int Arch Otorhinolaryngol 2014;18:319-321. \\ Address for correspondence Ligia Morganti, MD, Department of \\ Otorhinolaryngology, UFMG, Avenida Alfredo Balena, 190 Belo \\ Horizonte, Minas Gerais 30130100, Brazil \\ (e-mail: ligia_og@yahoo.com.br).
}

\author{
Abstract \\ Keywords \\ - ethmoid sinus \\ - sinus mucocele \\ - hemianopsia
}

Paranasal sinus mucoceles are benign cystic lesions, filled with mucus, occurring due to an obstruction of involved sinus ostium. They are indolent, locally expansive, and destructive. Surgical treatment must be performed and, when done at the correct time, may prevent sequelae. We present a case of ethmoid sinus mucocele with orbit involvement and permanent optical nerve injury.

\section{Introduction}

Paranasal sinus mucoceles are benign indolent cystic lesions filled with mucus and recovered by respiratory epithelium occurring due to an obstruction of sinus ostia. ${ }^{1,2}$ They are locally expansive and destructive, causing resorption, erosion, and bone remodeling. ${ }^{2}$

Mucoceles are often unilateral and may involve more than one sinus. Most commonly affected are the frontal (60 to 65\%) and ethmoidal (20 to 30\%) sinuses, followed by the maxillary (10\%) and sphenoidal (2 to $3 \%$ ) sinuses. ${ }^{3}$

\section{Case Report}

The patient was a 46-year-old woman with diagnosis of severe myopia since childhood, with routine periodic monitoring. There were no other comorbidities. In 2007, a sudden nasal hemianopsia appeared in the left eye. After further ophthalmologic investigation, she was referred for neurologic imaging study. A computed tomography (CT) scan showed soft tissue occupying some of posterior left ethmoid cells, adjacent to the lamina papyracea. In this topography, it presented tenuous irregularities that could correspond to erosion of its walls (-Figs. 1 and 2). Magnetic resonance imaging (MRI) showed hyperintense image in T2 sequence, with no significant enhancement by contrast (-Figs. 3 and 4).

Possible ethmoidal mucocele with orbital involvement and optic nerve injury was considered during ear, nose, and throat evaluation. Surgical treatment was proposed then. For per- sonal reasons, the patient opted not to be operated at the time, and she returned 2 years later with the same ophthalmic presentment. Another CT scan identified just slight thickening of the mucous lining and hypodense content in some posterior ethmoid cells, bilaterally, mostly in left side, with no difference in papyraceous plate (-Fig. 5).

With no specific treatment performed, tomographic study in 2012 showed no lesions, but ophthalmic involvement remained unchanged ( - Figs. 6 to 8). Current eye examination found vision in the right eye of 20/100 and in the left eye, finger counting (temporal).

\section{Discussion}

Paranasal sinus mucoceles are more common during the third and fourth decades, with slight predominance of male sex. ${ }^{2}$ It is mainly related to previous sinus surgery, face trauma, and chronic rhinosinusitis. ${ }^{4}$ Nasal tumors, fibrous dysplasia, and cystic fibrosis are rarely associated causes, and the last one should be remembered in cases in children. ${ }^{5,6}$

Paranasal sinus mucoceles are oligosymptomatic, slowgrowing, expansive lesions. However, they may be locally aggressive and evolve to neurologic, skin, or eye complications. Substances such as prostaglandin E2 and collagenase are detectable in the capsule of the mucocele and seem to be related to its ability to resorb bone. ${ }^{3,7}$

Imaging study allows easy identification of the injury and its extent. CT scan is the ideal method for detecting bone received

October 7, 2013

accepted

November 16, 2013

published online

January 16, 2014
DOI http://dx.doi.org/

10.1055/s-0033-1364168. ISSN $1809-9777$.
Copyright $(2014$ by Thieme Publicações License terms Ltda, Rio de Janeiro, Brazil 


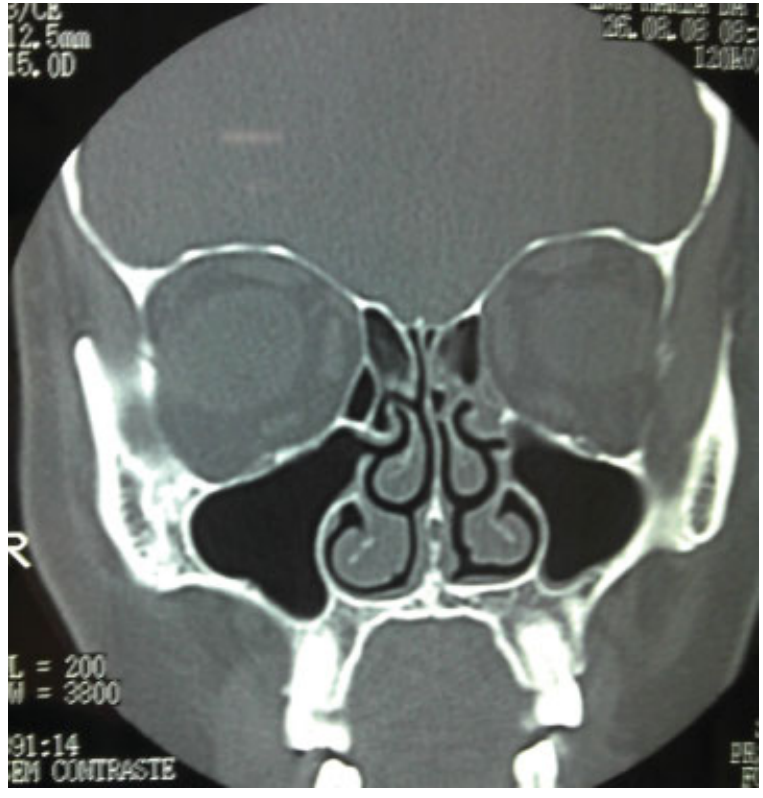

Fig. 1 Coronal bone computed tomography image shows soft tissue content occupying some posterior left ethmoid cells, adjacent to the lamina papyracea.

erosion and remodeling. MRI should be performed when intracranial invasion is suspected. ${ }^{8}$

Usually, ocular complications arise from absorption of papyraceous lamina, with possibility of proptosis due to displacement of the eyeball by the mucocele. Depending on the extent of bone erosion, the optic nerve can be compressed or stretched, resulting in transient or permanent visual impairment.

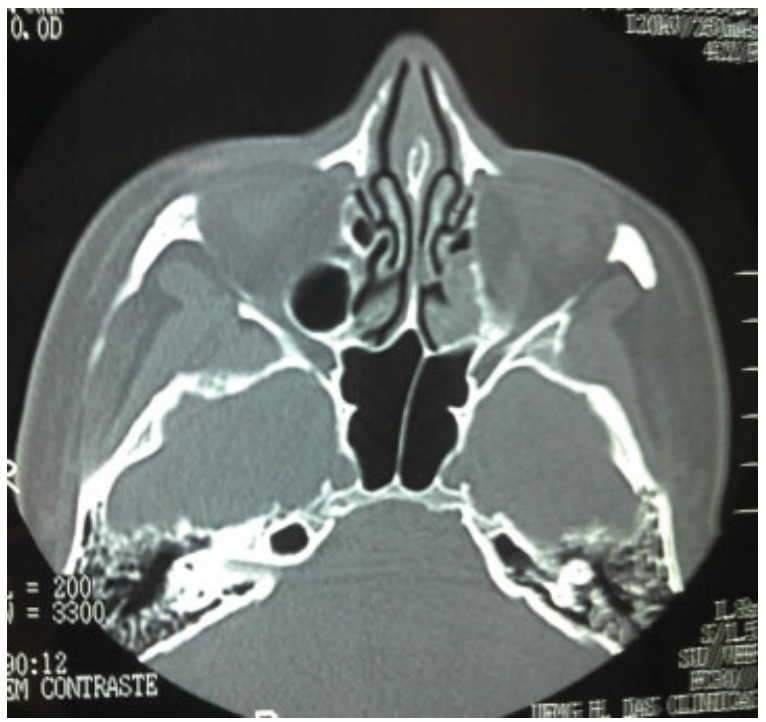

Fig. 2 Axial bone computed tomography reveals irregularities possibly corresponding to erosion of lamina papyracea.

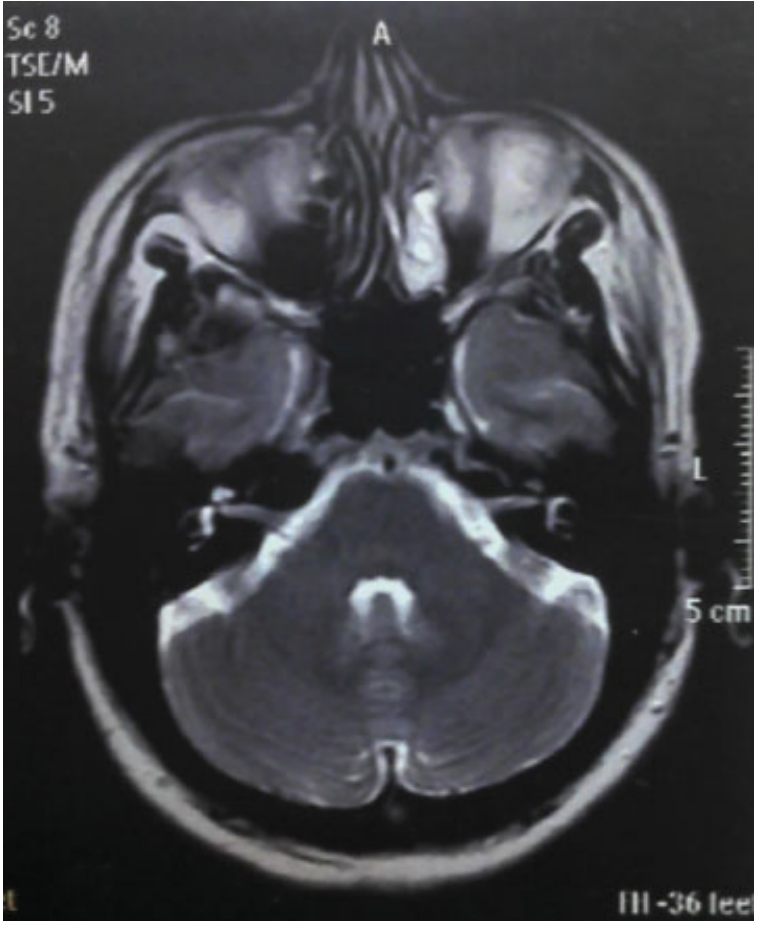

Fig. 3 Axial magnetic resonance imaging sequences show hyperintense signal in the corresponding tissue.

Surgical treatment must always be performed and, when done in a timely manner, may avoid optic nerve injury or even allow it to recover in cases of mild involvement.

Nasal endoscopic surgery has developed in the latest decades, and the endonasal approach is widely used. It has fewer postsurgical complications and minimal mucosal damage and offers a better postoperative view for close observation. ${ }^{7,8}$

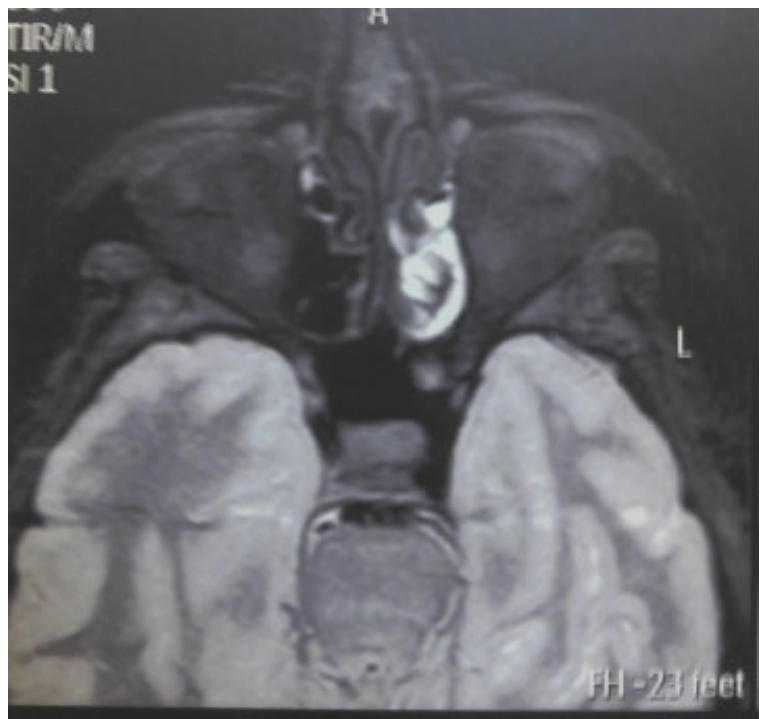

Fig. 4 Axial magnetic resonance imaging sequences show hyperintense signal in the corresponding tissue. 


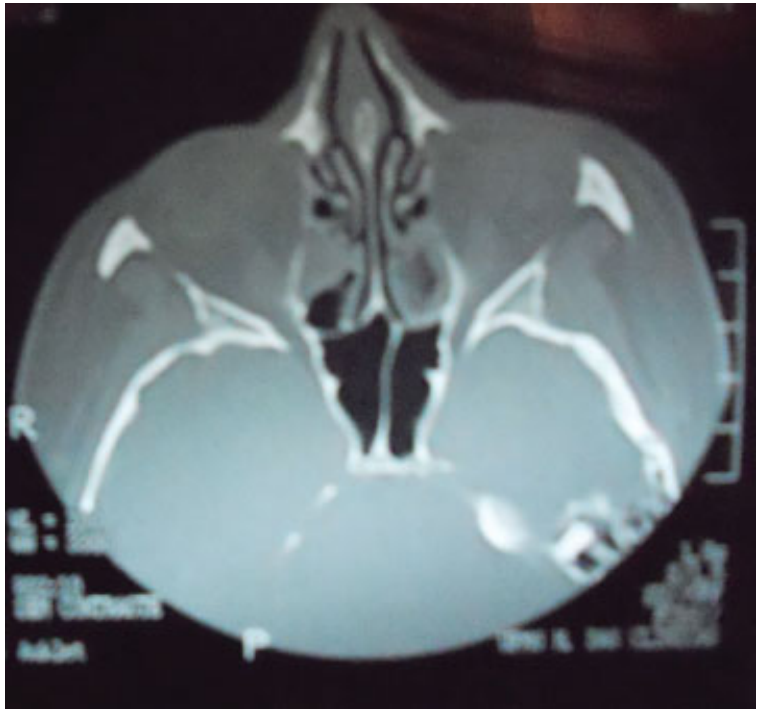

Fig. 5 Axial bone computed tomography reveals thickness of mucous lining and small content in posterior ethmoid cells, bilaterally, mostly in the left side.

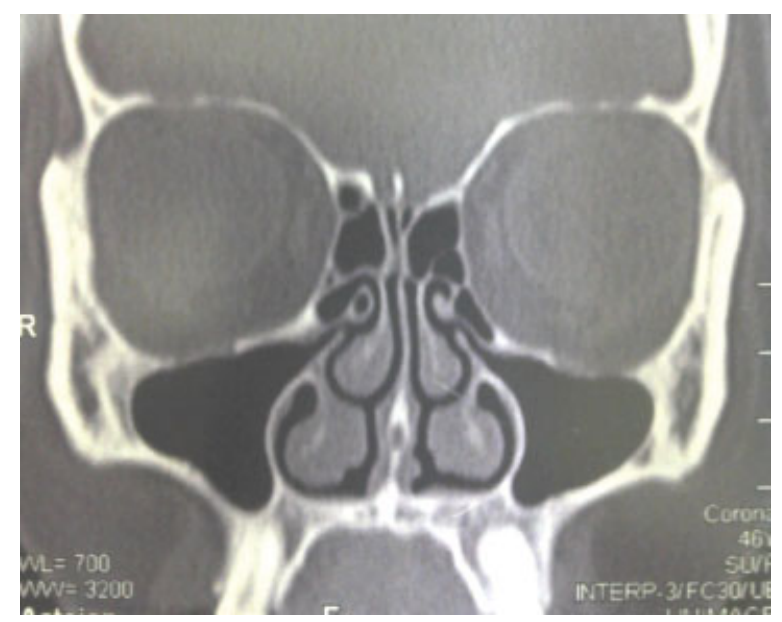

Fig. 6 Coronal bone computed tomography with normal findings.

\section{References}

1 Capra GG, Carbone PN, Mullin DP. Paranasal sinus mucocele. Head Neck Pathol 2012;6(3):369-372

2 Siu A, Singh A, Roberti F. Rapid improvement of cranial neuropathies after endoscopic resection of sphenoid sinus mucocele. Skull Base Rep 2011;1(1):23-26

3 Obeso S, Llorente JL, Pablo Rodrigo J, Sánchez R, Mancebo G, Suárez C. Mucoceles de senos paranasales. Nuestra experiencia en 72 pacientes. Acta Otorrinolaringol Esp 2009;60(5):332-339

4 Lee KC, Lee NH. Comparison of clinical characteristics between primary and secondary paranasal mucoceles. Yonsei Med J 2010; 51(5):735-739

5 Nicollas R, Facon F, Sudre-Levillain I, Forman C, Roman S, Triglia JM. Pediatric paranasal sinusmucoceles: etiologicfactors, manage-

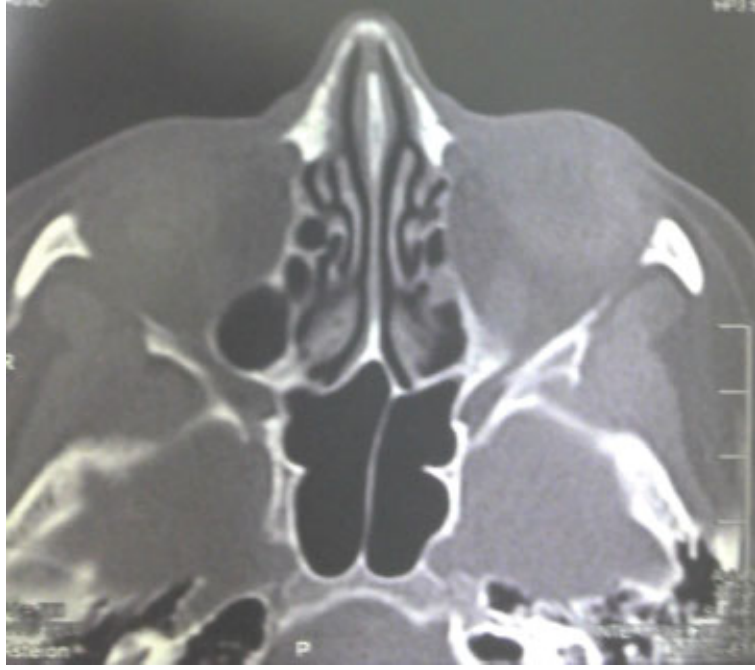

Fig. 7 Axial bone computed tomography with normal findings.

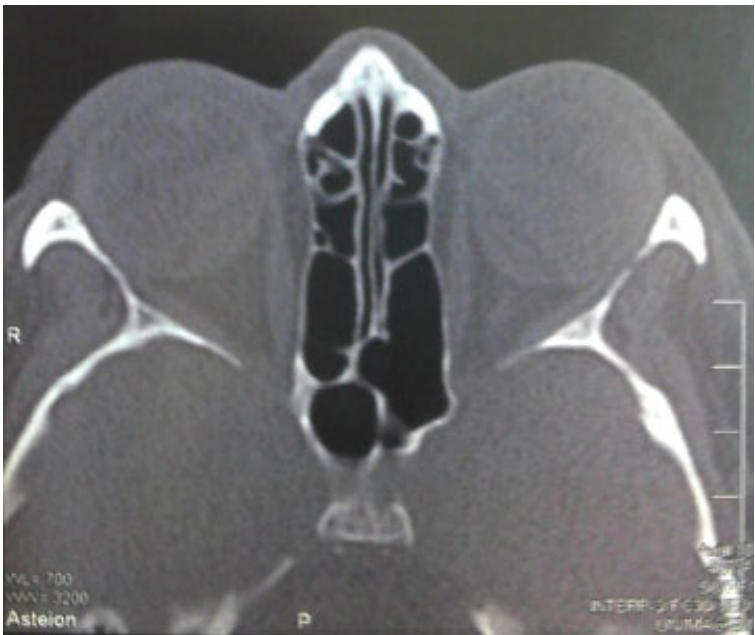

Fig. 8 Another axial bone computed tomography with no abnormalities.

ment and outcome. Int J Pediatr Otorhinolaryngol 2006;70(5): 905-908

6 Sih T, Godinho R, Franco LP, Piltcher O. Cystic fibrosis: Brazilian ENT experience. Int J Otolaryngol 2012;204696:7

7 Kim DW, Sohn HY, Jeon SY, et al. Ethmoidal mucocele presenting as oculomotor nerve paralysis. Clin Exp Otorhinolaryngol 2013; 6(2):103-106

8 Devars du Mayne M, Moya-Plana A, Malinvaud D, Laccourreye O, Bonfils P. Sinus mucocele: natural history and long-term recurrence rate. Eur Ann Otorhinolaryngol Head Neck Dis 2012; 129(3):125-130 